\title{
Nerroby
}

\section{Focal seizures due to chronic localized encephalitis}

\author{
Theodore Rasmussen, M.D., Jerzy Olszewski, M.D.* and \\ Donald Lloyd-Smith, M.D.
}

OCCASIONAL SPECIMENS of scarred, atrophic brain removed for the relief of focal cerebral seizures at the Montreal Neurological Institute have shown striking perivascular collections of round cells, particularly in less severely damaged areas of these specimens. In the past this perivascular cuffing has been attributed to the effect on the brain of recurring seizures, with recognition, however, that this was a rather unsatisfactory explanation since the great majority of surgical specimens removed from patients with equally frequent focal seizures do not show this change. Histologic studies of surgical specimens from three children recently operated upon for intractable focal seizures suggest that this microscopic picture may indicate the presence of an unsuspected, more or less localized, chronic encephalitis that has smoldered along over a period of years. The clinical and histologic data on these three children will be reported in some detail.

The most complete study from the pathologic standpoint was made in the last of the three patients to appear. This case will be discussed first, since it seems to clarify interpretation of the train of events in the other two.

\section{CASE REPORTS}

Case 1. An 18 month old boy developed seizures following an infected scratch behind the right ear. Focal right-sided seizures became increasingly frequent, despite maximal doses of anticonvulsants.
Removal of the left frontal lobe, carried out six months after the onset of seizures in a fruitless attempt to stop them, provided an opportunity to compare the microscopic picture at that time with that shown at autopsy three and a half months later.

Birth and early development of this child were normal, and there were no significant illnesses until April 1955 at 18 months of age, when the parents noted a scratch behind the right ear. The following day swelling in this region was noted and the temperature rose to $104^{\circ} \mathrm{F}$. The temperature subsided the next day after administration of penicillin, but the swelling behind the ear continued to discharge bloody fluid for one week.

The child seemed entirely well for two months, but in July he became unusually irritable one day and vomited the following morning. That afternoon he seemed dizzy and soon after was noted to stare and salivate; he then developed clonic jerking movements of the right side of the body. The clonic seizure soon became generalized and persisted for an hour before the convulsion was stopped by administration of chloroform.

A similar attack occurred a month later in August 1955, and from then on milder right-sided seizures recurred several times daily. During the next three months his usual quiet, pleasant bebehavior changed and he became somewhat irritable and destructive. During this period his parents felt that his speech was becoming somewhat less clear than it had been.

In November the right arm became completely useless and hung limply by his side for three days.

From the department of neurology and neurosurgery, McGill University and the Montreal Neurological Institute, Montreal, Quebec, Canada.

Present address: Laboratory of Experimental Neuropathology, College of Medicine, University of Saskatchewan, Saskatoon, Canada. 


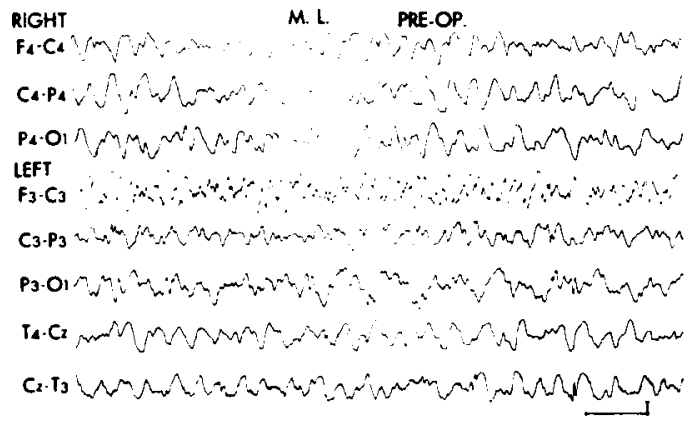

Fic. 1. Case 1. Sample from an electroencephalogram made during the first week in hospital. Horizontal scale indicates 1 second, vertical scale represents 100 microvolts.

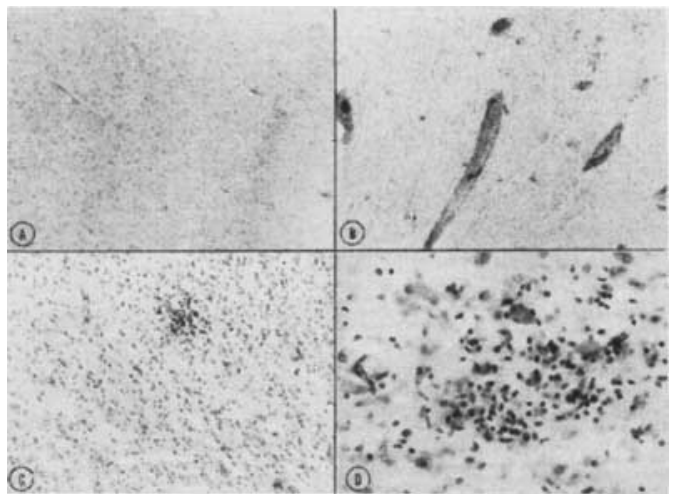

Fic. 2. Case 1. Surgical specimen from left frontal lobe. A. Nissl stain, 165x. B. Nissl stain, 400x. $C$, Nissl stain, 55x. D. Gold chloride sublimate impregnation, 165x.

Strength then returned in the arm, but his gait gradually became unsteady.

He was admitted to the Montreal Neurological Institute December 8, 1955, five months after his first seizure. He was a cooperative two year old boy, talking and playing normally between frequent major and minor right-sided seizures. There was a slight but definite right hemiparesis. He was somewhat dehydrated, but once that was corrected the urinalysis and white blood cell count were normal. There was a moderately severe hypochromic anemia. The spinal fluid findings were normal, as were skull and chest roentgenograms and a pneumoencephalogram.

An electroencephalogram showed widespread slow-wave abnormalities from both sides of the head, with frequent seizure discharges in the left frontocentral region (figure 1 ).

The patient continued to have many right-sided seizures daily, despite maximal doses of Dilantin, phenobarbital, Tridione, Mysoline, Mesantoin, and bromides. At times paraldehyde was necessary to stop episodes of status epilepticus. Sleep for several hours each day induced with Avertin given

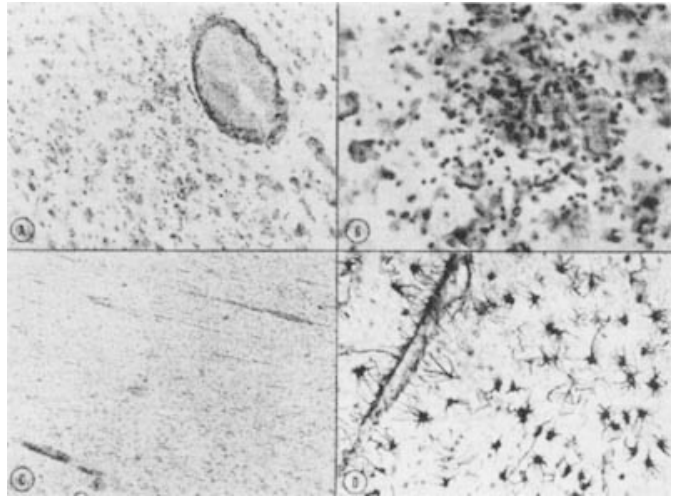

Fig. 3. Case 1. Sections fr.m autopsy. A. Right frontal lobe, Nissl stain, 55x. B. Left frontal lobe, Nissl stain, 55x. C. Left cuneus, Nissl stain. 165x. $D$. Left frontal lobe, Nissl stain, 400x.

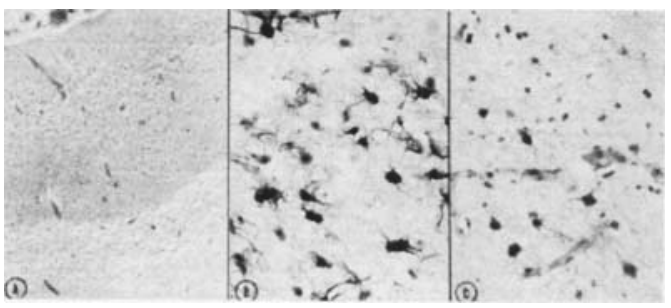

Frc. 4. Case 1. Sections from autopsy. A. Left cuneus, hematoxylin-phloxin-safranin stain, $55 x$. B. Left central region, gold chloride sublimate impregnation, $400 x$. C. Right central region, gold chloride sublimate impregnation, $400 x$.

rectally failed to control the seizures which recurred each time as he awakened. Between attacks, however, he was able to play with his toys if not too heavily medicated.

The slight right hemiparesis gradually became more marked. On January 10, 1956, six months after the onset, he was operated upon and the right frontal lobe was removed in a futile effort to interrupt the almost daily episodes of status epilepticus which were thought to be producing the slowly progressive hemiparesis. The cortex appeared grossly normal, but the cortical electroencephalogram showed epileptiform activity throughout the entire exposed area, most marked anteriorly. The postoperative cortical electroencephalogram showed the epileptiform abnormality persisting unchanged in the central and parietal regions.

Seizures recurred as he awakened from the anesthetic and continued as before operation. A postoperative electroencephalogram two weeks later showed the same diffuse slow-wave abnormality as before, with most marked epileptiform activity in the left central region. Bromides, administered until the blood level reached $280 \mathrm{mg}$. per cent, 
lessened the attacks little if at all. Keeping the child asleep with paraldehyde was the only effective way of stopping the attacks. For several weeks he was allowed to wake up two or three times each day to eat but he often vomited his meals with a seizure; it finally became necessary to feed him by stomach tube while he was asleep in order to maintain adequate nutrition. His course had been quite afebrile before operation and during the first two postoperative months. In March 1956 salivation with the seizures became an increasing problem. Despite the tracheotomy which was carried out at this time, it was difficult to keep his lungs clear. The seizures continued, his general condition gradually deteriorated, and he died April 24, 1956, three and one-half months after operation and nine months after his first seizure.

The initial spinal fluid examination in December 1955 showed 3 cells per cu.mm. and $18 \mathrm{mg}$. per cent protein. Because histologic examination of the surgical specimen removed in January 1956 showed evidence of encephalitis (figure 2), the cerebrospinal fluid was examined periodically during his postoperative course, starting four weeks after operation when it was felt that any pleocytosis due to the operation itself would have subsided completely. Weekly examinations in February, four to eight weeks after operation, showed 20 to 55 white cells per cu. mm., mainly polymorphonuclear cells in the first two specimens and mainly mononuclear cells in the next three specimens. The protein levels varied from 66 to 98 mg. per cent. The colloidal gold curve on February 29 was 255543200 . In March, two months after operation, despite continuation of the seizures and deterioration in his general condition, two examinations a week apart revealed only 2 and 6 lymphocytes per cu. $\mathrm{mm}$. and the protein, sugar, and chlorides were normal. On April 23, the day before death, the spinal fluid showed 2 lymphocytes per cu. mm. and a protein of $17 \mathrm{mg}$. per cent.

\section{Pathology}

In the surgical specimen removed six months after his first seizure and three and one-half months before death, there were multiple small accumulations of inflammatory cells scattered in a random manner throughout the cortex and white matter but less numerous in the latter (figure 2 $A$ and $C$ ). They were composed of small round cells and microglia with occasional polymorphonuclear cells (figure 2B). There was a small amount of perivascular cuffing, predominantly in the cortex, but present also in the white matter (figure $2 A$ and $C$ ). The meninges were thick and infiltrated by inflammatory cells, predominantly lymphocytes. There were marked hypertrophy and hyperplasia of astrocytes diffusely throughout both the gray and white matter (figure 2D).

Autopsy examination was limited to the brain, which weighed $795 \mathrm{gm}$. and appeared grossly normal except for the surgical amputation of the left frontal lobe. Blocks were cut from various areas of the convexities and basal ganglia of the two cerebral hemispheres, cerebellum, pons, and medulla and stained by both tinctorial and metallic methods.

Sections from the right hemisphere were normal, except for the presence of a few small round cells in the perivascular spaces around some of the larger vessels and occasional round cells in the leptomeninges (figure 3A).

Sections from the left hemisphere showed intensive perivascular cuffing by round cells in both the cortex and white matter in all areas, similar to that seen in the surgical specimen (figure 3B). There were numerous diffuse and patchy areas of infiltration of the cortex and white matter by inflammatory cells, predominantly microglia and small round cells with occasional polymorphonuclear cells (figure $3 \mathrm{C}$ and $\mathrm{D}$ ). Red cells were numerous in all regions, especially in the cortex. Numerous areas showed laminar loss of nerve cells in the fifth and sixth layers, with spongy degeneration (figure 4A). The astrocytes were hypertrophied and increased in number as compared with the right hemisphere (figure $4 B$ and $C$ ).

There was a similar but less marked inflammatory process in the basal ganglia on the left, while the corresponding region on the right was normal, except for the presence of a few compound granular corpuscles and an occasional round cell around a few of the larger vessels.

The pons, medulla, and cerebellum were normal, except for the presence of a few inflammatory cells in the leptomeninges and a slight reduction in number of the Purkinje cells.

\section{Summary of Pathologic Findings}

In the surgical specimen there were many nodules of inflammatory cells distributed in a random manner throughout the cortex and to a lesser extent in the white matter. There was minimal but definite perivascular cuffing in both the cortex and white matter, less marked in the latter. The cortex and white matter were well preserved otherwise.

At postmortem examination three and one-half months later, there was early laminar spongy degeneration in the cortex with intense perivascular cuffing and, as in the surgical specimen, diffuse infiltration of inflammatory cells in both grav and white matter. These changes were limited almost exclusively to the left cerebral hemisphere.

\section{Comment}

To summarize findings in this patient, two months after an apparently insignificant and perhaps unrelated skin infection behind the right ear, an encephalitis developed whose only manifestation during the first few months was frequently recurring focal seizures. Two or three months after the onset his behavior gradually became more irritable and his speech a little less clear. Four months after the onset, 


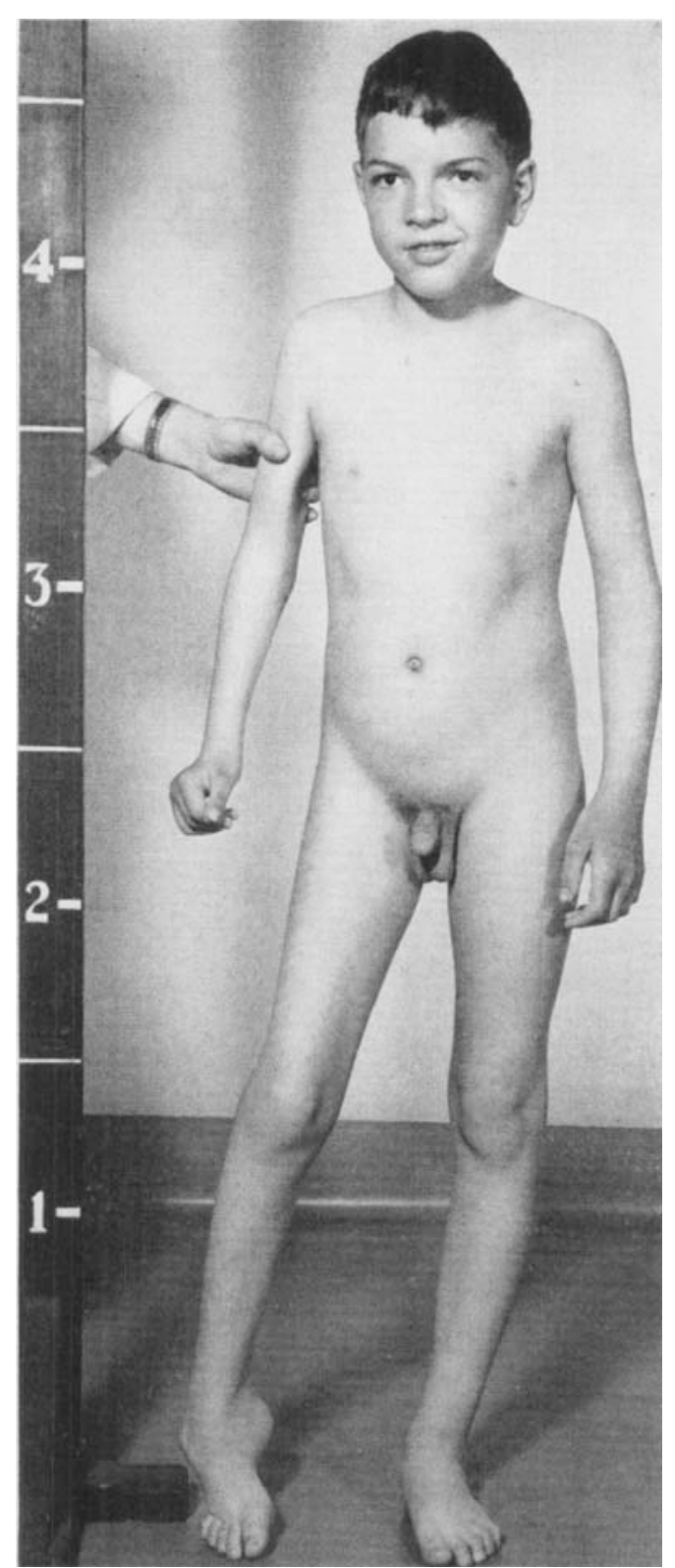

Fig. 5. Case 2. Patient at age 11 years, six years after onset of his illness.

a slight but progressive right hemiparesis appeared. Death ensued nine months after the onset. Despite the progressive character of the disease and ultimately fatal outcome, it remained almost completely limited to the left cerebral hemisphere.

Histologic changes consisted of subacute and chronic encephalitis, with intense astrocytic reaction and early laminar spongy degeneration of the cerebral cortex. In view of the extensiveness of the inflammatory process demonstrated in the autopsy studies, it is of particular interest that the spinal fluid was entirely normal during the four and one-half month period of hospitalization, except for the four weekly examinations made during his second postoperative month. It seems unlikely that the pleocytosis and elevation of protein found in these specimens could be due to reaction from the operation, but this possibility cannot be ruled out completely. Unfortunately no spinal fluid examinations were made during the first five months of the illness. Our initial impression that the frequent focal seizures themselves were responsible for the slowly progressive right hemiparesis is doubtless incorrect. In retrospect, it seems clear that an encephalitis was present and was responsible for the hemiparesis as well as for the seizures.

Case 2. An 11 year old boy (figure 5) was studied thoroughly over a period of several years at the Sick Children's Hospital in Toronto. Following the onset of focal seizures at age five, he developed two episodes of status epilepticus which left him with a permanent right hemiparesis. Frequent focal seizures persisted, ultimately requiring left hemicorticectomy at age 11 years.

This boy had a normal birth and early development, the only illness being measles at one year of age. In 1949 at age five, without any antecedent illness or apparent cause, episodes of twitching of the right side of the face appeared and recurred many times daily. The twitching soon spread to involve the right arm and leg as well. A month or so after the onset, a series of generalized seizures occurred in which he was unconscious for several hours. On awakening there was a marked weakness of the right arm which proved to be permanent. A similar convulsive episode two months later was followed by a persisting weakness of the right leg as well. There was apparently no speech disturbance on either of these occasions, despite the fact he had been considered to be right-handed.

Following each of these convulsive episodes he was hospitalized in Toronto and studied completely, and on each occasion the spinal fluid examination and pneumoencephalogram were normal (figure $6 \mathrm{~A}$ ). The seizures continued essentially unchanged. In April 1951, two years after the onset, a repeat pneumogram showed for the first time slight but definite enlargement of the left lateral ventricle (figure $6 \mathrm{~B}$ ). An exploratory

-We are indebted to Dr. W. A. Hawke and Dr. W. S. Keith at the Sick Children's Hospital in Toronto for providing us with their detailed data and roentgenograms which were of great help in analyzing case 2 . 

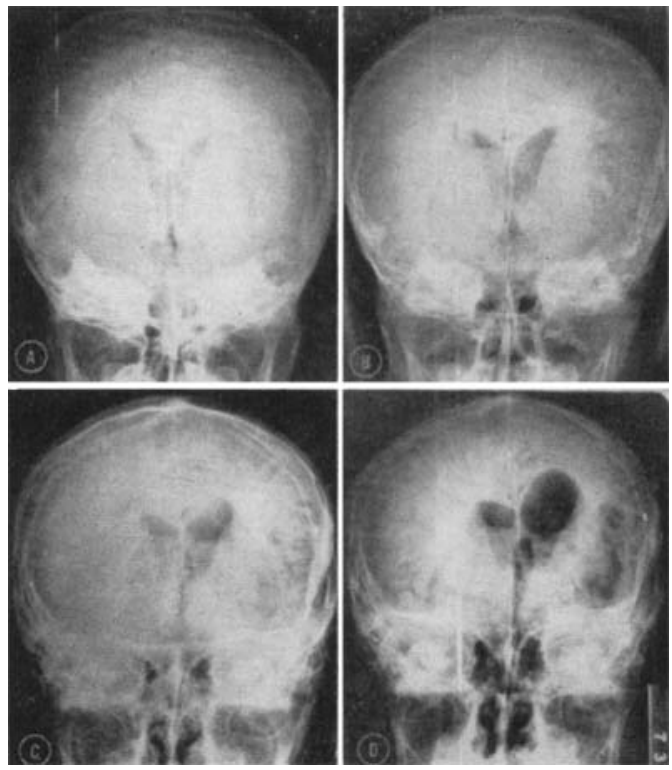

Fig. 6. Case 2. Pneumoencephalograms. A. 1949 age five years. $B .1951$, age seven years. $C$. 1954, age ten years. D. 1955 , age 11 years.

craniotomy and cortical biopsy were then carried out. No gross lesion was seen and the biopsy specimen on histologic examination was reported as showing only diffuse gliosis of moderate degree. The spinal fluid was examined after this operation and showed a total protein of $22 \mathrm{mg}$. per cent, negative Wassermann reaction, and a normal colloidal gold curve.

The right hemiplegia persisted and the rightsided seizures continued as often as every five minutes, with the longest seizure-free intervals rarely exceeding one or two days. In July 1954 the pneumogram was repeated again, and showed more marked evidence of atrophy of the left cerebral hemisphere (figure 6C). During the ensuing year the patient was confined to bed most of the time due to frequency of the seizures, and as a result he developed contracture of the right ankle in a position of equinovarus.

On admission to the Montreal Neurological Institute in April 1955 he was a quiet, alert, wellbehaved boy, with a marked spastic right hemiplegia (figure 5) and a complete right homonymous hemianopsia. Only slight voluntary wrist movements were present; there were strong mass flexion movements at the fingers but no individual finger movements and no voluntary movement at the ankle or toe joints. There was moderate smallness of both the right arm and leg. There was reduced appreciation of pain and light touch over the right half of the body, absent joint sense in the right hand and foot, reduced vibration sense in the right arm and leg, and a gross defect in two-point discrimination and figure writing on the right hand and foot.
Many seizures were witnessed, all starting with a sensory aura on the right, usually appearing first in the leg, occasionally in the arm, rarely starting in the face. This sensory aura was followed by unresponsiveness, a bending forward at the waist, a tonic elevation of the right arm, and then clonic jerking of the right arm as the head and eyes turned, usually to the right, but occasionally to the left. Often there was also twitching of the right side of the face and right leg. He spoke promptly and normally immediately after the attacks were over.

Psychologic testing showed an I.Q. rating of 53 on the Wechsler intelligence scale for children, with a verbal I.Q. of 61 and a performance I.Q. of 51. On casual conversation, however, he did not impress one as being mentally retarded to this degree.

Blood, urine, and spinal fluid findings were normal. The skull roentgenogram showed only slight smallness of the left hemicranium, but the pneumogram showed evidence of marked destruction of the left hemisphere, with only slight enlargement of the right lateral ventricle anteriorly (figure 6D). The electroencephalogram showed fairly marked slow-wave abnormality bilaterally, with focal epileptogenic activity in the left frontal, left temporal, and right parietal areas.

On May 10, 1955 a left hemicorticectomy was carried out. The hemisphere was composed of small, somewhat yellowed gyri of moderately increased firmness, but there were no areas of gross destruction. The hemisphere was removed completely peripheral to the striatum and thalamus ( figure 7).

He had a minor seizure the first postoperative day and a low grade temperature elevation during the first two postoperative weeks; otherwise the postoperative course was uneventful. There was no speech disturbance; motor function in the right leg returned to the preoperative level by the end of the first postoperative day and in the right arm by the fourth postoperative day. The postoperative electroencephalogram showed the usual posthemicorticectomy flat, low voltage record on the left, with the same pattern on the right as was seen preoperatively, consisting of some slow-wave abnormality with sporadic sharp waves in the right parietal region.

Three weeks postoperatively, just before discharge, psychologic tests showed the I.Q. had risen slightly from 53 to 58 , probably due to some improvement in attention span.

In September 1955, four months after operation, surgical correction of the equinovarus deformity was carried out at the Sick Children's Hospital in Toronto. Psychometric examination at that time showed no marked change from the preoperative tests carried out there the year previously.

$\mathrm{He}$ has remained seizure-free since his first postoperative day and has received no anticonvulsant medication since operation. Eight months after operation he started going to school for the first 

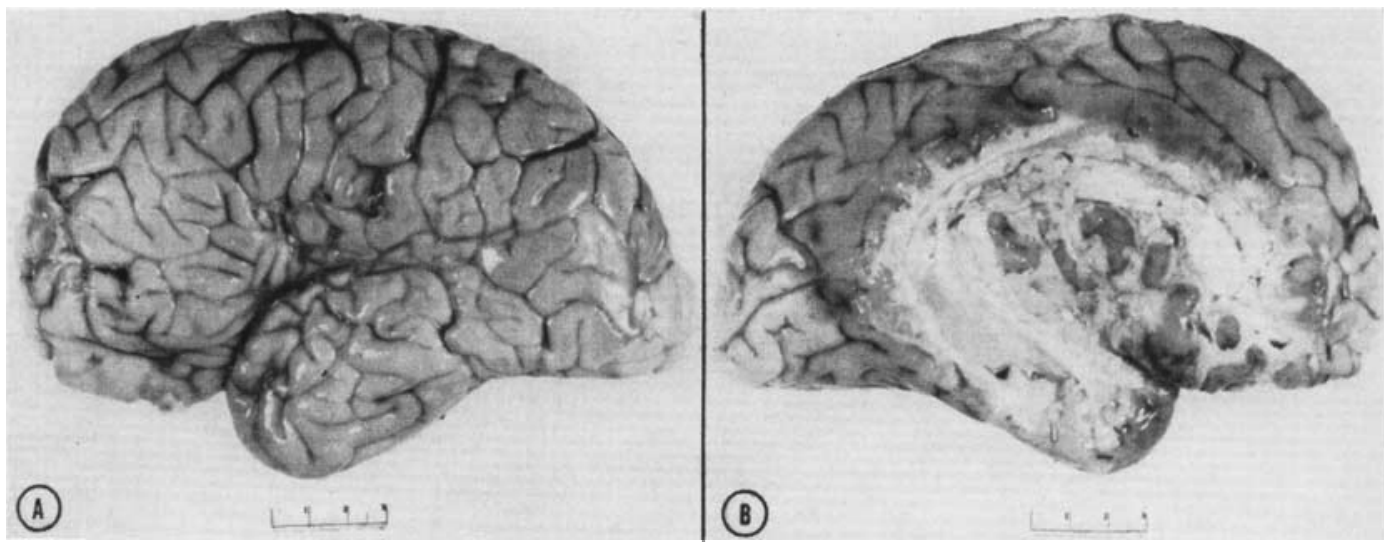

Fic. 7. Case 2. Surgical hemicorticectomy specimen.

A. Lateral surface. B. Medial surface.

time in his life, attending a class for slow learners. At the latest follow-up report one year and eight months after operation, he was reported to be making good progress in school work and getting along happily with his schoolmates.

\section{Pathology}

The convolutional patterns of the specimen showed markedly narrowed gyri in the Sylvian region (figure 7 ), with the remaining convolutions slightly narrow and most of them moderately increased in consistency. On histologic examination there were areas of spongy degeneration of the cortex distributed irregularly over the entire hemisphere, but most marked in the Sylvian region. In some areas this spongy degeneration occupied the whole thickness of the cortex except the first layer. In these regions the nerve cells were markedly reduced in number and the tissue consisted of a loose network of glial fibers with small microscopic cysts between them (figure 8A). In areas where the cortex was better preserved, a few vessels showed well marked perivascular cuffing by small round cells (figure 8B). Scattered throughout the cortex were a few inflammatory nodules made up of small round cells and microglia. In other areas the cortex was diffusely infiltrated with these inflammatory cells and showed beginning spongy destruction. Similar inflammatory changes were present in the white matter, marked in some areas and minimal in others. There were marked hyperplasia and hypertrophy of the astrocytes present diffusely throughout the gray matter, and to a lesser extent in the white matter (figure 8C). The myeline in the white matter was well preserved except in the convolutions which were markedly degenerated.

\section{Pathologic Summary}

In the hemicorticectomy specimen which was removed six years after the onset of the illness, there was evidence of a chronic encephalitic process in the gray and white matter. In many regions the cortex was so severely damaged that it was

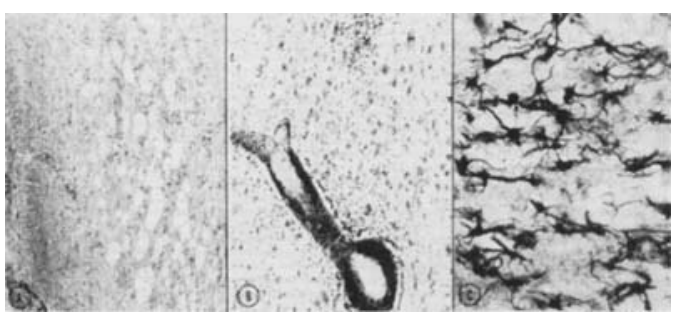

Fig. 8. Case 2. Surgical specimen. A. Left parietal lobe, hematoxylin-phloxin-safranin stain, 55x. B. Left frontal lobe, Nissl stain, 165x. C. Left central area, gold chloride sublimate impregnation, 400x.

reduced to a narrow layer of spongy glial tissue. In better preserved areas, chronic inflammatory cells formed cuffs around blood vessels and were scattered diffusely throughout the tissue.

\section{Comment}

This patient was actually the first one encountered. From the clinical standpoint it was our impression preoperatively that his history represented a typical instance of a child developing postictal hemiplegia as a result of seizures due to some pre-existing fixed lesion, such as a cerebral cicatrix or some metabolic disorder. The histologic evidence of an inflammatory process came as a complete surprise, in view of the lack of any of the usual signs of encephalitis in this patient's clinical story. There was a history of measles at age one, but no infection of any kind was reported at or just before the onset of the seizures at age five. Pathologically the lesions were more advanced than in the first patient, showing more destruction and less active inflammatory reaction, but the latter was identical in type and distribution. 

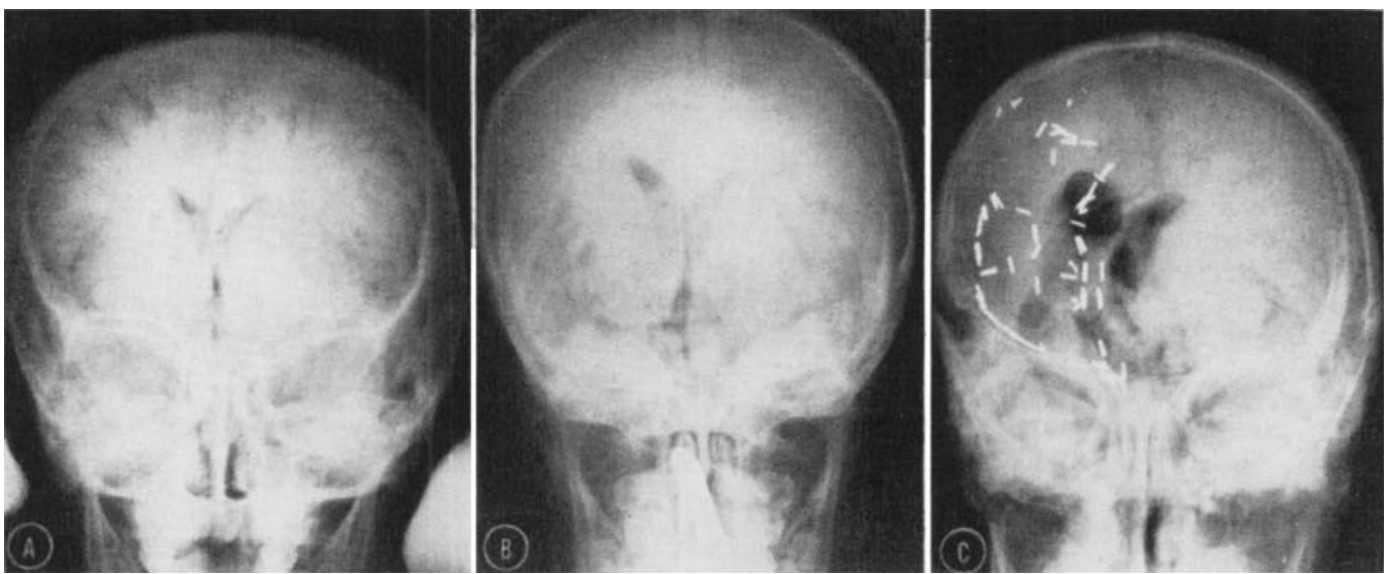

Fic. 9. Case 3. Pneumoencephalograms. A. 1951, age three and one-half years. B. 1952, age five years. C. 1956, age eight years.

Case 3. An eight year old boy developed his first seizure with a mild attack of "flu" at age two and one-half. Left-sided seizures persisted and after a year a slowly progressive left hemiparesis developed. Right frontal lobectomy at age six failed to stop the seizures or the progressive hemiparesis. Right hemicorticectomy was carried out five years after the onset.

This patient showed no evidence of birth injury and developed normally until age three and one-half. At this time he had a mild attack of "flu," for which the family physician was called to the house. While the physician was making his examination, the boy had a generalized convulsive seizure. He was hospitalized for a few days and then discharged, apparently well.

Two months later in March 1951, he developed recurring left-sided clonic seizures of one minute's duration. He was again hospitalized and studied in his home city of Columbus, Ohio. Clinical neurologic data, skull roentgenograms, and pneumogram were all normal (figure 9A). The spinal fluid showed three polymorphonuclear cells and five lymphocytes per cu. $\mathrm{mm}$. and a protein of $23 \mathrm{mg}$. per cent. The electroencephalogram showed a moderately severe generalized dysrhythmia, with focal abnormalities in the right occipitoparietotemporal area. Since the air studies showed no evidence of an expanding lesion, the consulting neurosurgeon suggested, on the basis of electroencephalographic and clinical evidence, that the child had a low grade encephalitis. On Dilantin and phenobarbital, however, the patient was seizure-free and apparently well for the next year.

In February 1952, at age four and one-half, one year after the first attack, the seizures recurred and persisted, occurring five to six times daily. He became hyperactive and a moderate behavior

- Case 3 was referred by Dr. Kenneth Abbott, Columbus, Ohio, to whom we are indebted for providing detailed clinical data and roentgenograms of his repeated studies, as well as microscopic slides from the frontal lobectomy. problem, and gradually developed slight weakness of the left arm and leg. He was studied again in October 1952. The spinal fluid at this time showed four polymorphonuclear cells per cu. mm., a trace of globulin, and a normal colloidal gold curve. At this time, nearly two years after his initial "flu" and convulsion, he was referred to one of the authors at the University of Chicago Clinics for consideration of surgical therapy of the seizures, in the hope of preventing progression of hemiparesis.

The patient exhibited at this time (November 1952) a mild left hemiparesis with appropriate reflex changes. The blood, urine, and spinal fluid were all normal, the latter showing no cells, negative Pandy, protein of $22 \mathrm{mg}$. per cent, and chlorides $123 \mathrm{mEq}$. per liter. The pneumogram, which had been normal a year and a half earlier, showed moderate dilatation of the body and frontal horn of the right lateral ventricle, with a $5 \mathrm{~mm}$. shift of the septum pellucidum toward this side; also there was clear evidence of enlargement of the subarachnoid spaces over the right frontal region (figure 9B). The posterior half of the right lateral ventricle was similarly enlarged. The electroencephalogram showed diffuse bilateral slow-wave abnormality, most marked in the right frontal and central region, and also bilaterally synchronous sharp waves in both frontal regions, with the greatest amplitude and sharpest wave forms on the right side. We concluded that a progressive atrophic process was present and surgery not indicated unless the process became stationary and more localized.

The left hemiparesis gradually increased until he was confined to a wheelchair most of the time. The left-sided seizures became still more frequent until it was deemed necessary in October 1953, nearly three years after the onset of the illness, to remove the right frontal lobe in an effort to prevent recurring episodes of status epilepticus. Histologic examination of the specimen removed sug- 
gested the diagnosis of encephalitis (see discussion of pathology).

Following frontal lobectomy, the seizures became less frequent for a time and strength in the leg improved slightly so that he could walk, although with a hemiplegic limp. During the next year the seizures again increased in frequency and the hemiparesis progressed.

He was referred back for further consideration of surgical therapy for his seizures, and was admitted to the Montreal Neurological Institute in March 1956. Minor seizures were occurring every few minutes, in which he would stop talking, slump forward, and show twitching movements of the left arm and left side of the face. It was necessary to keep him in bed or tied in a wheelchair, wearing a football helmet to prevent banging his forehead constantly in his seizures. He was dull in appearance, with marked gingival hypertrophy from heavy Dilantin medication. There was much salivation and his respirations were noisy with loud moist rales and rhonchi. He was able to talk during some of the shorter spells; during the larger attacks he would be unresponsive for a minute or two and the clonic movements would involve the entire left side of the body.

There was smallness and a moderately spastic paralysis of the left extremities with appropriate reflex changes. It was not possible to examine the sensory system adequately, but appreciation of pinprick seemed reduced and delayed over the left half of the body.

The urine, blood, and spinal fluid were normal. Skull films showed a small skull, with the internal diameters unchanged from films made three and a half years earlier, suggesting there had been little or no brain growth during this time. There was a slight selective smallness of the right side of the calvarium, in addition.

The pneumogram showed a marked increase in dilatation of the right lateral ventricle as compared with the 1952 examination two and one-half years earlier, with a marked shift to the right of the septum pellucidum and third ventricle (figure $9 \mathrm{C})$. The changes were almost as marked in the posterior part of the ventricular system, and the left lateral projection showed that the right temporal horn was also proportionally enlarged. The electroencephalogram showed evidence of a large active epileptogenic area throughout the right central, parietal, and posterior temporal regions (figure 10A).

On March 13, 1956, five years after the onset and two and one-half years after the right frontal lobectomy, he was operated upon again and a wide exposure made of the right hemisphere behind the area of the previous frontal removal (figure 11). There was marked thickening of the arachnoid, with adhesions to the dura most marked over the central region adjacent to the site of the previous operative exposure. The convolutions were all small and of increased consistency, but there were no areas of gross destruction of brain, ex-

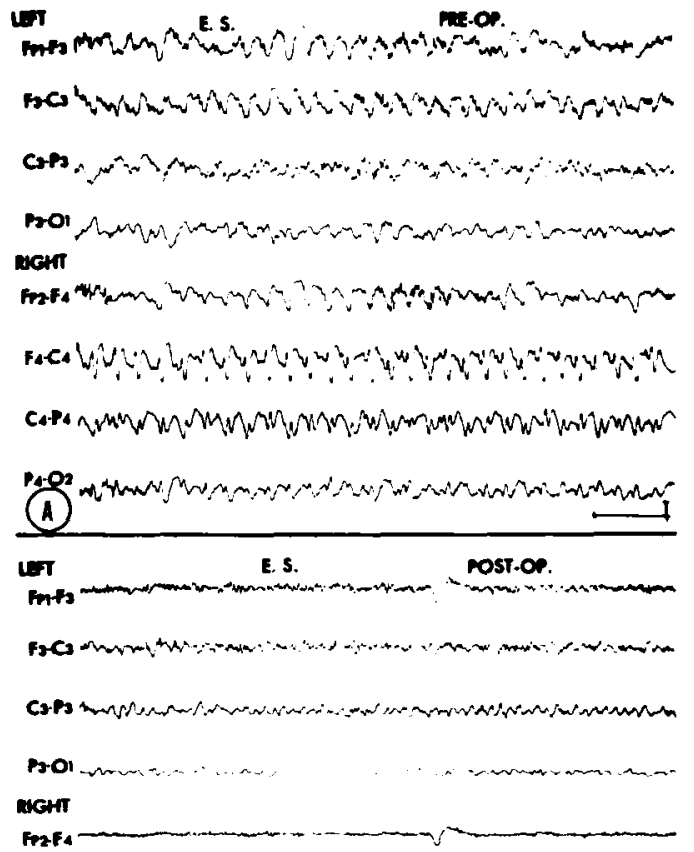

FAC

CAP4

P.On

(B)

Fic. 10. Case 3. Electroencephalograph samples. $A$. Before right hemicorticectomy. $B$. After hemicorticectomy. Note improvement in record from left (unoperated) hemisphere. Horizontal scale indicates 1 second, vertical scale represents 100 microvolts.

cept at the site of the previous frontal lobectomy. The cortical electroencephalogram showed high amplitude spikes coming from all exposed areas. A complete right hemicorticectomy was carried out, removing the entire hemisphere peripheral to the striatum and thalamus.

Postoperatively he had a low grade elevation of temperature for the first week, but no seizures except for a 10 second episode of twitching of the left arm on the first postoperative day. By the third postoperative day he was much more alert than he had been preoperatively. On discharge three and one-half weeks after operation, he was walking with less support than on admission. Some voluntary movement at the left elbow had returned and there was some reduction in spasticity; otherwise the left hemiplegia was essentially unchanged. It was now possible to test sensation a little more completely. Appreciation of light touch was markedly reduced over the left side. Pinprick was felt but reduced and was localized poorly on the left side, whereas it was localized accurately on the right. 


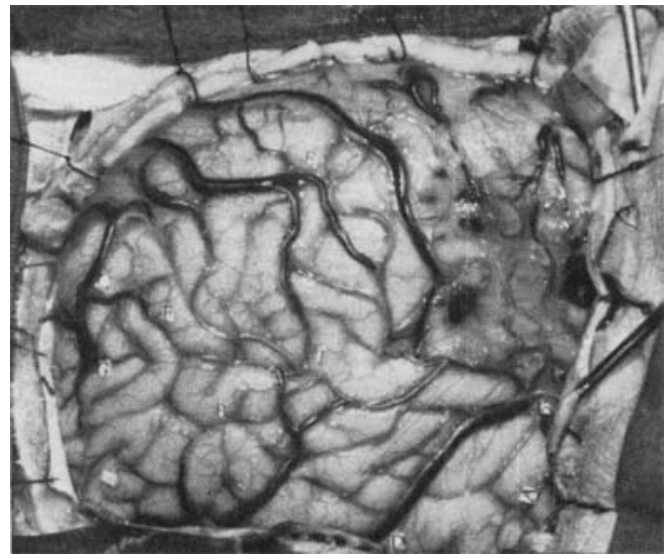

Fic. 11. Case 3. Operative photograph. Letters indicate areas of maximum abnormality in cortical electrogram. Letters $A$ and $D$ are on temporal lobe, $C$ and $G$ on occipital lobe, $E$ and $F$ on parietal lobe.

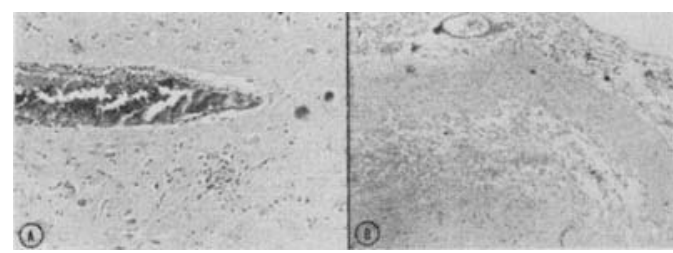

Fic. 12. Case 3. Sections from right frontal lobe (1953). A. Hematoxylin-eosin stain, 165x. B. Hematoxylin-eosin stain, 55x.

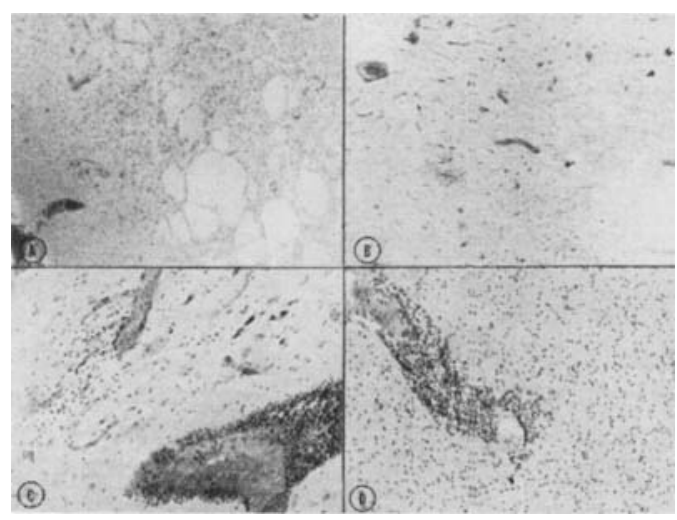

Fig. 13. Case 3. Sections from hemicorticectomy specimen (1956). A. Central area, hematoxylinphloxin-safranin stain, 55x. B. Parietal lobe, hematoxylin-phloxin-safranin stain, 55x. C. Central area, hematoxylin-phloxin-safranin stain, 165x. D. Central area hematoxylin-phloxin-safranin stain, 165x.

An electroencephalogram three weeks after operation showed marked improvement, with a flat record over the right side and normal activity from the left hemisphere, except for some trains of low amplitude 4 per second waves recorded from the left central region (figure $10 \mathrm{~B}$ ).
Two months after operation he was walking without assistance, but with a hemiplegic gait. There was marked improvement in mentality, alertness, and personality. At latest report, one year and four months after operation, he is still seizure-free and taking only a small daily dose of phenobarbital. He walks well, with the limp lessened considerably by the use of an ankle brace. He has started going to school and is beginning to read and write a little.

\section{Pathology}

Specimens from the frontal lobe removed in 1953 showed a scattering of glial nodules and definite perivascular round cell infiltration in both gray and white matter (figure 12A). There were also prominent patches of laminar necrosis and focal cortical atrophy (figure 12B).

The hemicorticectomy specimen removed two and one-half years later showed more severe tissue destruction and less extensive inflammatory changes, as compared with the earlier frontal lobe specimens. In the more rostral part of the hemicorticectomy specimen, most of the cortex was surrounded by dense fibrous astrocytic tissue in which only an occasional nerve cell persisted (figure 13A). The first cortical layer was spared and showed the presence of gemistocytic astrocytes. The white matter beneath these areas of spongy degeneration showed perivascular cuffing by small round cells and intense gliosis. Occasionally a relatively well preserved gyrus was adjacent to one badly damaged. More caudally in the specimen, only small areas of this spongy degeneration could be seen (figure 13B). In the more normal appearing areas of cortex, there were occasional small areas of infiltration by round cells and microglia and a small amount of perivascular cuffing by small round cells around some of the vessels (figure 13B and C). These changes, which were seen in the underlying white matter as well (figure 13D), were least marked in the occipital region. Astrocytic proliferation was extensive, both in the spongy areas and in areas that were better preserved.

\section{Pathologic Summary}

The right frontal lobe specimen removed three years after the onset showed inflammatory changes, with some areas of chronic spongy degeneration. The hemicorticectomy specimen removed two and one-half years later showed much more extensive and more marked spongy degeneration, with persistence of the inflammatory changes in the less severely damaged areas of the hemisphere.

\section{Comment}

In this patient, the early "flu" gives a possible explanation for etiology of the inflammatory brain disease, but its prolonged course and absence of other clinical evidence of cerebral inflammation seem to set the proc- 
ess apart from the usual concept of encephalitis. Comparison of the two pathologic specimens from this patient suggested that the disease had burned itself out in some areas, leaving behind its mark in the form of spongy degeneration and diffuse astrocytic gliosis, while in other areas evidence of an active inflammatory process was still present at the time of the hemicorticectomy five years after the onset.

\section{DISCUSSION}

We believe these three patients represent various stages and degrees of the same pathologic process. We call this an encephalitis on histologic grounds, recognizing that we have no indication as to the etiology of this condition. However, localization of the lesions and their character are more consistent with a virus encephalitis ${ }^{1}$ than with a postinfectious perivenous encephalitis or with allergic encephalitis. ${ }^{2,3}$ It is of some interest that both case 1 and case 3 had minor systemic inflammatory episodes at the beginning of the illness. Case 2 had apparently uncomplicated measles at one year of age, four years before the onset of seizures, but there is no record of any systemic infection immediately preceding this onset.

The chronicity of the illnesses and the relatively restricted location of the lesions in these three patients would seem to set them apart from ordinary cases of encephalitis, but similar prolonged courses have been reported in cases of inclusion encephalitis, ${ }^{4,5}$ although in other instances the course of similar or related encephalitides has been more acute. ${ }^{0-8}$

If these three patients were indeed all suffering from encephalitis, then it seems clear that this disease was present over a prolonged period of time, causing seizures and a slowly progressive hemiparesis without any febrile reaction or coma such as customarily accompany encephalitides. Case reports showing histologic evidence of active encephalitic lesions still present long after acute episodes of proved viral encephalitis ${ }^{9-11}$ may give some support to the concept that the encephalitis in our three patients was of viral etiology.

Evidence of reaction in the spinal fluid (pleocytosis and elevated protein) was present in case 1 only during the second postop- erative month, and was absent in the several spinal fluid examinations carried out in case 2 and case 3. More frequent spinal fluid examinations over the course of the illness in the latter two might have shown evidence of some inflammatory reaction at some time.

Comparison of the two surgical specimens from case 3 removed three years and five and one-half years after the onset suggested that this encephalitic-like process may be self limited in some patients. After gradually destroying areas of brain over a period of years, evidence of the inflammatory process apparently disappeared, leaving behind a patchy laminar necrosis and widespread diffuse gliosis. This latter picture has been a fairly frequent finding in specimens removed for the surgical treatment of focal cerebral seizures. Occasionally there has also been present in these specimens perivascular cuffing and inflammatory glial nodules. These we have attributed in the past to tissue breakdown associated with frequent seizures. These three patients, we believe, suggest that some cases of focal epilepsy for which no definite cause is evident, such as birth trauma or anoxia, head injury, or vascular occlusion, may be due to an otherwise asymptomatic focal encephalitis. If excision of the scarred area should be carried out after the active process has disappeared and healing has occurred, evidence of the inflammatory nature of the original disease might be completely or almost completely absent.

Surgery in the active phase of the disease is probably futile, except for providing a clear pathologic diagnosis. The ultimately successful outcome of cases 2 and 3, successful to date at any rate, indicates that later in the course of the disease surgical removal of the involved areas of the brain, if sufficiently complete, can stop the seizures without rekindling the inflammatory process.

Suggestions for therapy in the active phase of the disease, when it might be possible to prevent destruction of brain tissue, must await determination of etiologic factors. Serial spinal fluid examinations at weekly or monthly intervals over relatively prolonged periods of time might well be important in identifying this group of patients, so that more detailed study of possible etiologic factors might be made before the fire has burned out and only 
the scarred evidence of earlier damage remains. Current speculations regarding the ability of some viruses to be dormant in the nervous system for long periods of time may be pertinent to the general problem.

\section{SUMMARY AND CONCLUSIONS}

A clinicopathologic report is made of three children suffering from a chronic illness, pro-

\section{REFERENCES}

1. Finley, K. H., and Horister, JR., A. C.: Western equine and $\mathbf{S t}$. Louis encephalomyelitis. The distribution and histological nature of central nervous system lesions. California Med. $77: 225,1951$.

2. Apams, R. D., and Kubrk, C. S.: The morbid anatomy of the demyelinative diseases. Am. J. Med. 12: $510,1952$.

3. Radermecker, J.: Systematique et Electroencéphalographie des Encéphalites et Encéphalopathies. EEG \& Clin. Neurophysiol. Supp. No. 5, Masson et Cie, Editeurs, Paris, 1956.

4. Malamud, N., Haymaker, W., and Pinkerton, H.: Inclusion encephalitis with clinopathologic report of three cases. Am. J. Path. 26:133, 1950.

5. DAwsoN, JR., J. R.: Cellular inclulsions in cerebral lesions of lethargic encephalitis. Am. J. Path. 9:7, 1933. ducing focal seizures and gradually producing severe damage to one cerebral hemisphere. The histologic appearance in each instance suggests the lesion is a chronic focal encephalitis. The etiology is undetermined, but the suggestion is made that it may be viral in nature. The possible role of similar focal encephalitic-like processes in producing certain cases of focal epilepsy is discussed.

6. Dawson, JR., J. R.: Cellular inclusions in cerebral lesions of epidemic encephalitis: Second report. Arch. Neurol. \& Psychiat. 31:685, 1934.

7. Axerartis, A. J., and Zezdis, L. J.: Encephalitis with intranuclear inclusion bodies. $A$ clinicopathological study. Arch. Neurol. \& Psychiat. 47:353, 1942.

8. HAYMAKER, W.: Herpes simplex encephalitis in man. With a report of three cases. J. Neuropath. \& Exper. Neurol. 8:132, 1949.

9. Norax, H. H., and Baxer, A. B.: Sequels of equine encephalomyelitis. Arch. Neurol. \& Psychiat. 49:398, 1943.

10. Noras, H. H.: Chronic equine encephalitis. Am. J. Path, 20:259, 1944.

11. Herzon, H., Shelton, J. T., and Bruyn, H. B.: Sequelae of western equine and other arthropod-borne encephalitides. Neurology 7:535, 1957.

Epilepsy is a disease of the "organ of mind," that is to say, of the highest and most complex, etc., centres. The symptomatology of the paroxysm is probably a universal symptomatology, is demonstrably nearly so. It may be said that insanity is more complex than epilepsy; not so, since epileptic paroxysms are not unfrequently followed by temporary insanity. The study of epilepsy, therefore, involves the study of some cases of insanity. These insanities are what $I$ have called after-conditions of the epileptic paroxysms. We ought, of course, to speak of epilepsies as we should do of insanities; for certainly, if two epileptics have different "warnings" of their fits, the "discharging lesion" is in a different part of the highest centres in the two cases. There are many epilepsies, and many insanities.

J. Hughlings Jackson in Ophthalmology and Diseases of the Nervous System, published in 1886. 


\section{Neurology}

Focal seizures due to chronic localized encephalitis

Theodore Rasmussen, Jerzy Olszewski and Donald Lloyd-Smith

Neurology $1958 ; 8 ; 435$

DOI 10.1212/WNL.8.6.435

This information is current as of June 1, 1958

\begin{tabular}{|ll|}
$\begin{array}{l}\text { Updated Information \& } \\
\text { Services }\end{array}$ & $\begin{array}{l}\text { including high resolution figures, can be } \\
\text { found at: } \\
\text { http://n.neurology.org/content/8/6/435.c } \\
\text { itation.full }\end{array}$ \\
& $\begin{array}{l}\text { This article has been cited by } 16 \\
\text { HighWire-hosted articles: } \\
\text { http://n.neurology.org/content/8/6/435.c } \\
\text { itation.full\#\#thetherarticles }\end{array}$ \\
& $\begin{array}{l}\text { Information about reproducing this } \\
\text { article in parts (figures,tables) or in its } \\
\text { entirety can be found online at: } \\
\text { hermissions \& Licensing } \\
\text { the_//www.neurnal\#permissions }\end{array}$ \\
& $\begin{array}{l}\text { Information about ordering reprints can } \\
\text { be found online: } \\
\text { http://n.neurology.org/subscribers/adver } \\
\text { tise }\end{array}$ \\
\hline &
\end{tabular}

Neurology ${ }^{\circledR}$ is the official journal of the American Academy of Neurology. Published continuously since 1951, it is now a weekly with 48 issues per year. Copyright $\odot 1958$ by the American Academy of Neurology. All rights reserved. Print ISSN: 0028-3878. Online ISSN: 1526-632X.

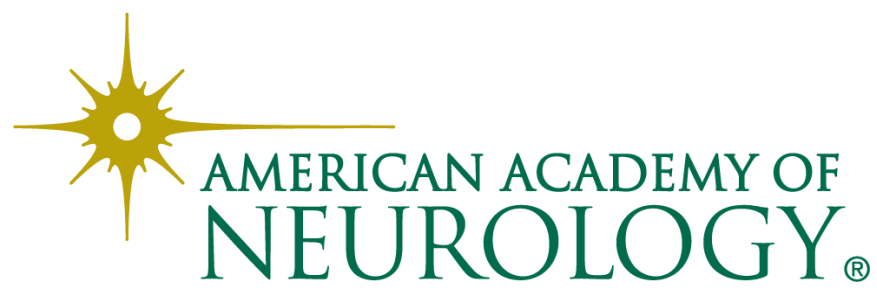

